\title{
Sintering Mechanism of silicon from $\mathrm{K}_{2} \mathrm{SiF}_{6}-\mathrm{Al}$
}

\author{
Zhaoke Pan ${ }^{1}$, Jinhua Wang ${ }^{2}$, Guizhai Zhang ${ }^{2 *}$ \\ ${ }^{1}$ Shandong Institute of Geological Sciences, Jinan, Shandong, 250013, P. R. China \\ ${ }^{2}$ Shandong Agriculture and Engineering University, Jinan, Shandong, 251100, P. R. China
}

\begin{abstract}
In order to clarify the reaction process of Si phase, Differential Scanning Calorimeter (DSC), as the main measurement, was used to prepare $\mathrm{Si}$ samples and monitor the sintering reaction process. Combined with X-ray diffraction analysis, the formation process of Si phase was summarized. The reaction between $\mathrm{K}_{2} \mathrm{SiF}_{6}$ and $\mathrm{Al}$ powders occurred at $580^{\circ} \mathrm{C}$, but not completed until $660^{\circ} \mathrm{C}$. The whole formation process of Si includes two different stages: One is the solid-solid reaction stage, the other is the solid-liquid reaction stage.
\end{abstract}

\section{Introduction}

Silicon does not exsit in the spontaneous word, at present, silicon is the raw material of production of silicone. Preparation of silicon powder has become a research focus. Many reports have been devoted to exploring the technique of producing silicon [1-4]. Silicon is normally produced by carbothermic reduction [5]. Silane $\mathrm{SiX}_{4}(\mathrm{Cl}$, $\mathrm{Br}, \mathrm{I})$ reduced by hydrogen or metal is also a silicon production way. In addition, molten salt electrodeposition is another silicon production method [6]. D. Elwell reported that silicon could be get from $\mathrm{K}_{2} \mathrm{SiF}_{6}$-flinak by electrodeposition [6, 7]. Now, carbothermal reduction is widely used industrial-scale production method.

However, Si-O bond is one of the most stable chemical bonds in the nature. To activate or cleave $\mathrm{SiO}_{2}$, its high bond energy needs to be overcome. Carbon thermal reduction occurs at $1200^{\circ} \mathrm{C}$, therefore, carbon thermal reduction is a high energy consumption method. Potassium silicon fluoride and aluminum powder are used to produce silicon in this paper. The potassium silicon fluoride is a byproduct of production potash fertilizer using potash feldspar. This study can realize waste recycling and also provide an important information for the silicon phase formation process.

The aim was to focus on the mechanism in the synthesis of silicon through the reaction between potassium silicon fluoride and aluminum powder, by Xray diffraction and the Differential Scanning Calorimeter (DSC).

\section{Materials and methods}

\subsection{Samples}

Silicon samples were prepared by the solid-state reaction method using potassium silicon fluoride and aluminum powder as the raw materials. Potassium silicon fluoride and aluminum (200 mesh size) were all in powder form. The weight ratio between the Potassium silicon fluoride and aluminum was kept at 1:0.2 in all the experiments. All powders were thoroughly mixed before using.

\subsection{Sample characterization}

High-temperature Differential Scanning Calorimeter (DSC) (SDT Q600 V8.0 Build 95) was carried out on the mixture of potassium silicon fluoride and aluminum powder. The DSC was carried out at normal atmosphere in the temperature range of $20^{\circ} \mathrm{C}-800^{\circ} \mathrm{C}$ (silicon easily oxidized before $800^{\circ} \mathrm{C}$ ) [8], with a heating rate of $15^{\circ} \mathrm{C} / \mathrm{min}$.

Based on the DSC results, the samples were then subjected to process at different temperatures using porcelain crucibles in muffle furnace and were further characterized by X-ray diffraction (XRD). Phase changes were monitored using a Rigaku D/MAX-rA Xray diffraction $(\mathrm{XRD})$ machine with $\mathrm{Cu} \mathrm{K} \alpha$ radiation, operated at $40 \mathrm{kV}$ and $40 \mathrm{~mA}$. The scanning speed used was $8 \mathrm{deg} / \mathrm{min}$ on the sinter.

Four different sintering temperatures of $570^{\circ} \mathrm{C}$, $580^{\circ} \mathrm{C}, 600^{\circ} \mathrm{C}$ and $670^{\circ} \mathrm{C}$ for $1 \mathrm{~h}$, respectively, were selected according to successive heating DSC curve up to $800^{\circ} \mathrm{C}$ (see Fig. 1). The samples were heated in the normal atmosphere at these temperatures. The heating rate was $15^{\circ} \mathrm{C} / \mathrm{min}$ during sintering process.

\section{Results and discussion}

\subsection{DSC analysis}

Fig. 1 shows the DSC results of a mixture of potassium silicon fluoride and aluminum powders. Apart from the exothermic peaks at $580^{\circ} \mathrm{C}$ and $600^{\circ} \mathrm{C}$ associated, an

\footnotetext{
*Corresponding author: zgzok2005@163.com
} 
endothermic peak at $660{ }^{\circ} \mathrm{C}$ (the melting point of pure aluminum) was detected.

According to the DSC curves, the reaction between $\mathrm{K}_{2} \mathrm{SiF}_{6}$ and $\mathrm{Al}$ powder started at about $570^{\circ} \mathrm{C}$, and then a stronger exothermic peak (Fig. 1, peak 1), caused by the formation of $\mathrm{KAlF}_{4}$ and $\mathrm{K}_{3} \mathrm{AlF}_{6}$, appeared. The subsequent gentle exothermic peak (Fig. 1, peak 2), caused by $\mathrm{Si}$ formed, is smaller than the peak 1 . The endothermic peak (Fig. 1, peak 3) was caused by pure aluminum melted. After $\mathrm{Al}$ melted, the reaction between the $\mathrm{K}_{2} \mathrm{SiF}_{6}$ and fused $\mathrm{Al}$ powder became stronger than that in the first two stages as the liquid phase ( $\mathrm{Al}$ ) increased diffusion rate of atom and enlarged the contacting area of reactants [9]. This indicated that the reaction between $\mathrm{K}_{2} \mathrm{SiF}_{6}$ and $\mathrm{Al}$ powder did not complete before $\mathrm{Al}$ melted.

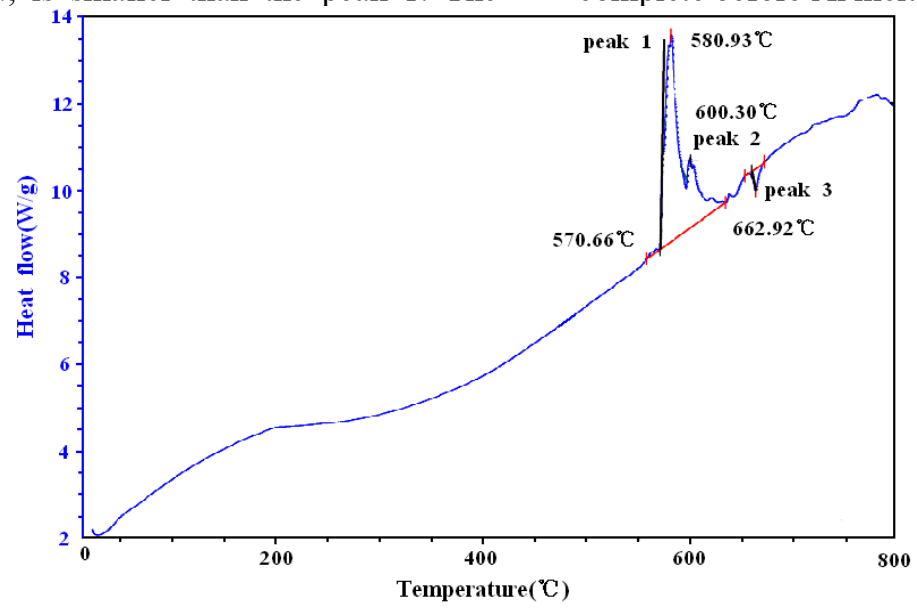

Fig. 1 DSC curve of mixture of $\mathrm{K} 2 \mathrm{SiF} 6: \mathrm{Al}=1: 0.2$ (black line), heated at a rate of $15^{\circ} \mathrm{C} / \mathrm{min}$

Reactions exhibit different mechanism. One belongs to solid-solid reaction, the other is solid-liquid reaction according to whether there is fused $\mathrm{Al}$ or not during the process.

\subsection{Formation of phase and identification}

In order to identify the phase formed at different stage, four different sintering temperatures of $570{ }^{\circ} \mathrm{C}, 580{ }^{\circ} \mathrm{C}$, $600{ }^{\circ} \mathrm{C}$ and $670{ }^{\circ} \mathrm{C}$, for $1 \mathrm{~h}$ were selected corresponding to the different stages of DSC curve in the sample with a mixture of $\mathrm{K}_{2} \mathrm{SiF}_{6}: \mathrm{Al}=1: 0.2$ (see Fig. 1). X-ray diffraction patterns of the samples obtained after heating treatment at different temperatures mentioned above are shown in Fig. 2 (a, b, c, d, e).

Fig. 2a

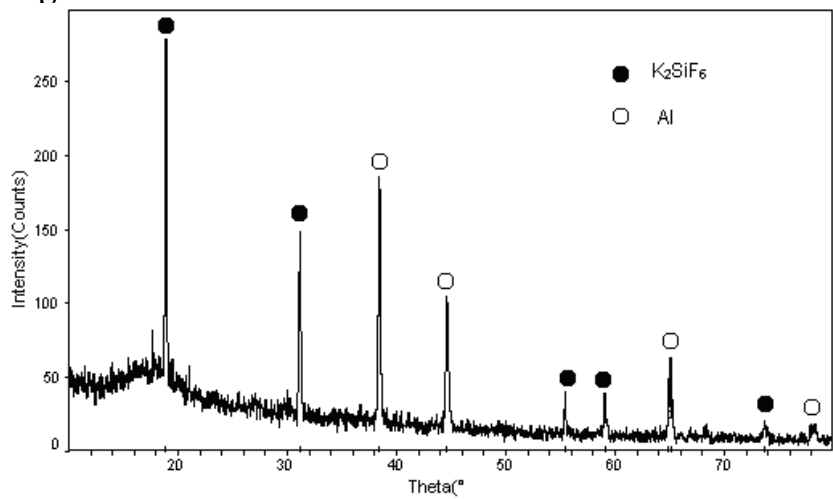

Fig. 2b

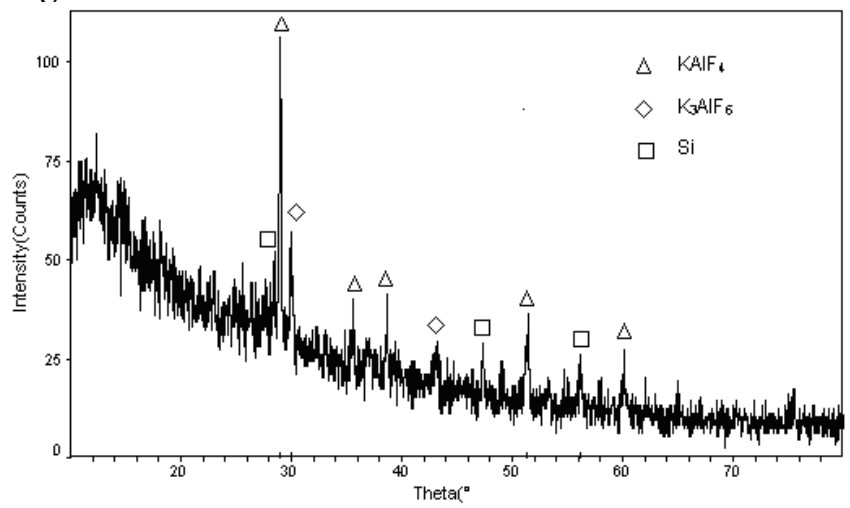


Fig. 2c

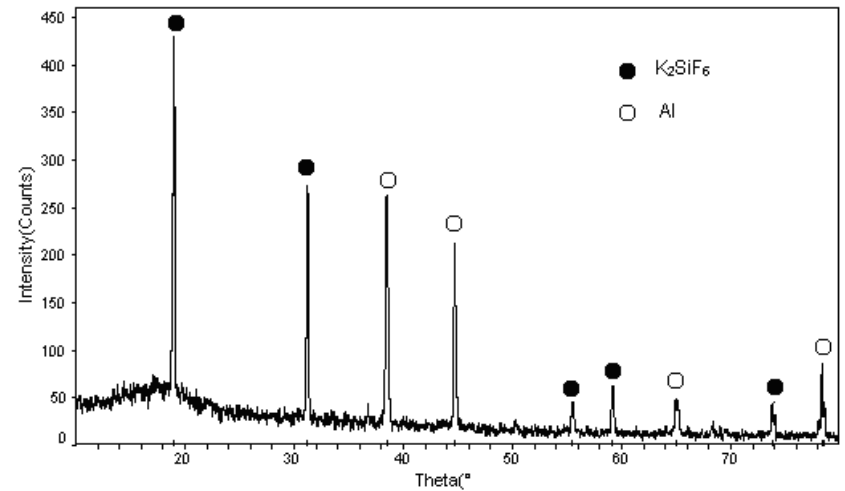

Fig. 2d

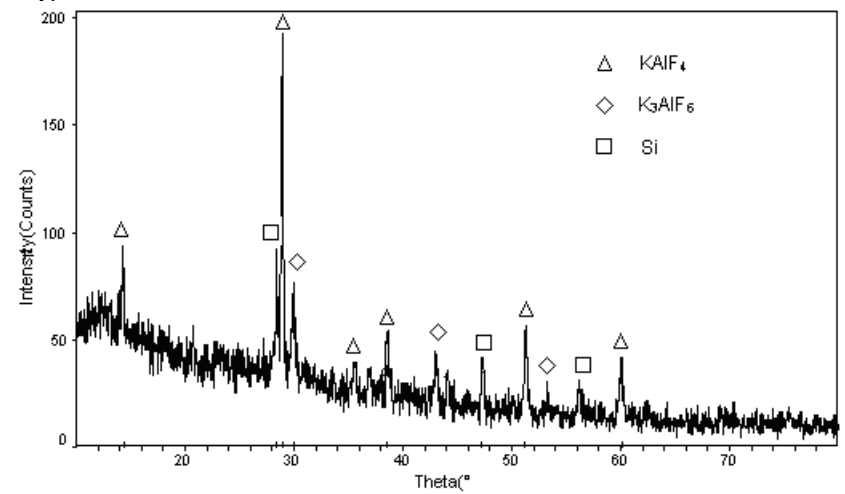

Fig. 2e

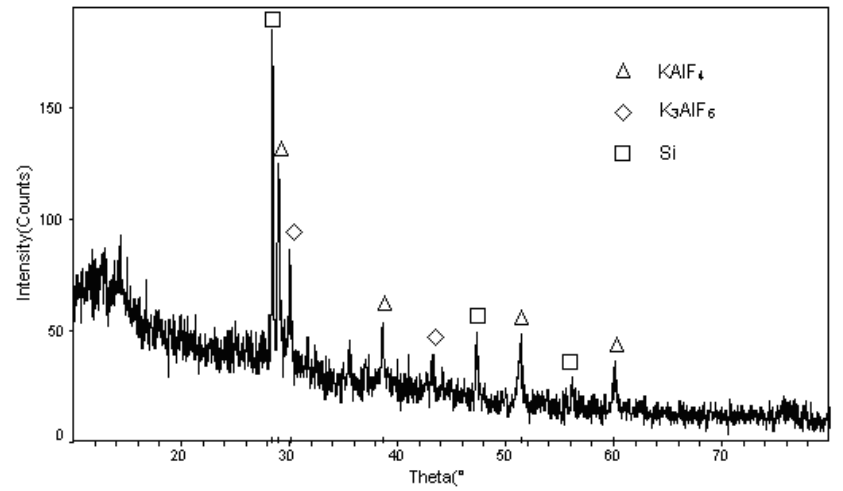

Fig. 2 XRD analysis of mixture of potassium silicon fluoride and aluminum (a) original and heated for $1 \mathrm{~h}$ at (b) $570{ }^{\circ} \mathrm{C},(\mathrm{c}) 580^{\circ} \mathrm{C},(\mathrm{d})$ $600^{\circ} \mathrm{C}$ and (e) $670^{\circ} \mathrm{C}$

According to X-ray diffraction patterns analysis of five different samples (see Fig. 2), the mass percent of aluminofluorides $\left(\mathrm{KAlF}_{4}\right.$ and $\left.\mathrm{K}_{3} \mathrm{AlF}_{6}\right)$ and silicon increased with sintering temperature. However, the silicon phase can hardly be identified in X-ray diffraction patterns when the temperature was below $600^{\circ} \mathrm{C}$ and only a little amount was generated as the temperature increased. So, the formation of silicon phase only causes small thermal effect at $600^{\circ} \mathrm{C}$. But, after the melting temperature of $\mathrm{Al}$, the silicon phase was the main phase.

Therefore, it is visible that the phase formation mechanisms are different before and after the melting temperature of Al. To understand the formation process more clearly, detail analysis was implemented at two different stages of solid-solid reaction and solid-liquid reaction below.

\subsubsection{Solid-solid reaction stage}

From the X-ray diffraction analysis results, it was found that no Si phases formed before $570^{\circ} \mathrm{C}$. At the initial stage of the reaction $\left(570^{\circ} \mathrm{C}\right)$, only $\mathrm{K}_{2} \mathrm{SiF}_{6}$ and $\mathrm{Al}$ phases were detected (Fig. 2 a and b). There was scarcely any difference between the two X-ray diffraction patterns.

As the sintering temperature increased to $580^{\circ} \mathrm{C}$ (see Fig. 1, the peak 1), many aluminofluorides $\left(\mathrm{KAlF}_{4}\right.$ and $\mathrm{K}_{3} \mathrm{AlF}_{6}$ ) were formed, fractional silicon phase that can be detected by X-ray diffraction appeared(Fig.2 c). when the sintering temperature reached $600^{\circ} \mathrm{C}$, silicon content slinghtly increased, aluminofluorides phases was still main phases (Fig.2 d).

At this stage, silicon phase has no clear increase for the reason that the growth of silicon is restricted by pinning action of pore [10]. On the other hand, 
migration-rate of materials is too slow to promote the growth of grain rapidly at this solid-solid reaction stage. Hence, it is hard to form large-scale silicon at this stage.

\subsubsection{Solid-liquid reaction stage}

when sintering temperature increased to $670^{\circ} \mathrm{C}$, the silicon phase was the main phase(see in Fig. 2(e)), which shows that reaction between $\mathrm{K}_{2} \mathrm{SiF}_{6}$ and $\mathrm{Al}$ powders has completed. At this temperature, residual $\mathrm{Al}$ melted and the flowing liquid phase (Al) increased the diffusion rate of atom and enlarged the contact area of reactants, which leads to a strong and complete reaction. This reaction may be written as:

$$
3 \mathrm{~K}_{2} \mathrm{SiF}_{6}+4 \mathrm{Al} \rightarrow 3 \mathrm{KAlF}_{4}+\mathrm{K}_{3} \mathrm{AlF} \mathrm{F}_{6}+3 \mathrm{Si}
$$

According to the structural theory of slag [11], both KAlF4 and K3AlF6 in their molten state may be regarded as molten mixtures of $\mathrm{KF}$ and AlF3. Therefore, Reaction (1) can be rewritten as:

$$
3 \mathrm{~K}_{2} \mathrm{SiF}_{6}+4 \mathrm{Al} \rightarrow 6 \mathrm{KF}+4 \mathrm{AlF}_{3}+3 \mathrm{Si}
$$

From the $\mathrm{KF}-\mathrm{AlF}_{3}$ phase diagram in Fig. 3 [12], it can be seen that the binary salt system of $\mathrm{KF}-\mathrm{AlF}_{3}$ at a ratio of 3:2 is located in the range where $\mathrm{KAlF}_{4}$ and $\mathrm{K}_{3} \mathrm{AlF}_{6}$ are the phases present at room temperature.

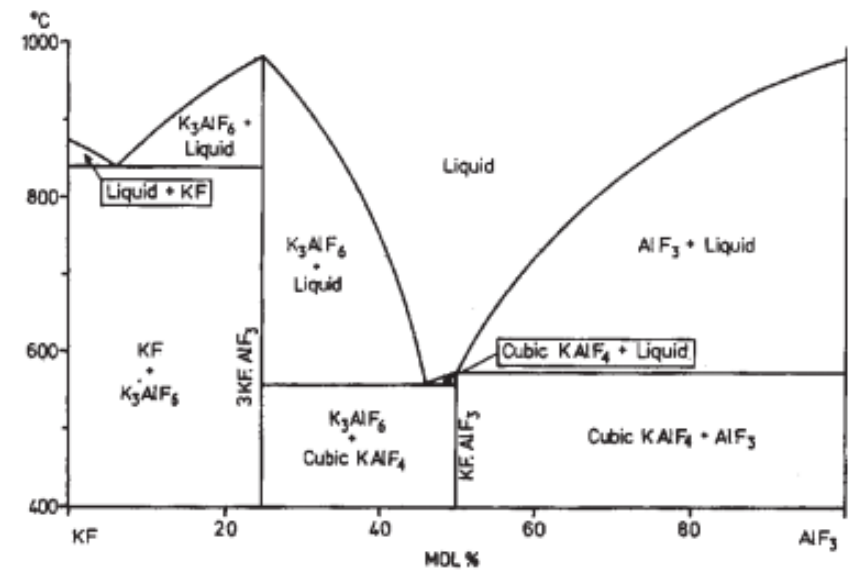

Fig. 3 Phase diagram of KF-AlF3 binary system [12]

\section{Conclusion}

The formation of silicon is investigated by DSC, and the mechanism is explored by a series of sintering experiments with the aid of X-ray diffraction analysis and sintering theories. It is found out that:

(1) The Si phase starts to form at $580^{\circ} \mathrm{C}$, but does not complete until the sintering temperature exceeds $660^{\circ} \mathrm{C}$ (the melting point of pure aluminum).

(2) Two different forming stages of Si phase are identified: one is the solid-solid reaction stage between $\mathrm{K}_{2} \mathrm{SiF}_{6}$ and $\mathrm{Al}$ powders, which generates a small amount of silicon. The other is the solid-liquid reaction stage, in which the molten $\mathrm{Al}$ promotes the reaction between $\mathrm{K}_{2} \mathrm{SiF}_{6}$ and $\mathrm{Al}$ powders.

\section{Acknowledgements}

The work was supported by the Doctor fund of Shandong Agriculture and Engineering University under Grant [NO. BSQJ201812]; and the Science and Technology Project of Shandong Province under Grant [NO. J17KB070].

\section{References}

1. Z.C. Dai and H. Z. Liu, Production and application of silicon compounds, Chengdu Science University Publications, Chengdu (1994).
2. J. Zhou, Y. G. Li and J.F. Niu, Journal of Hebei Institute of Technolgy 29, 39(2007).

3. R.L. Ueng, S.J. Jiang, and C.C. Wan, Analytica Chimica Acta, 536, (1-2):295-299 (2005).

4. C.C. Wan, S.J. Jiang and M.T. You, Journal of Analytical Atomic Spectrometry, 20, (11):1290 (2005).

5. W.H. Ma, D. Lu, B. Yang and Y.N. Dai, Acta Scientiarum Naturalium Universitatis Sunyatseni 48, 76 (2009).

6. D. Elwell and J. C. Growth, 52, 741(2002).

7. D. Elwell and G.M. Rao, Electrochimica Acta 27, 673(1982).

8. B.X. Lin, H. Yang, J. Zeng and N.N. Chen, Metallurgical Analysis 28, 62(2008).

9. Q.Z. Shi, Y.C. Liu, Q. Zhao and Z.Q. Ma, J. Alloy compound 4, 45(2007).

10. S.J. Guo, Powder sintering theory, Metallurgical Industry Publications, Beijing (1998).

11. B.Q. ZHang, H.S. Fang, L. Lu, M.O. Lai, H.T. Ma, and J.G. Li, Merallurgical and materials Transactions 34, 1727 (2003).

12. R. Chen, G.H. Wu, and Q.Y. Zhang, J. Am. Ceram 83, 3196 (2000). 